\title{
Strategi Marketing 4.0 pada Pasca Panen Ikan Lele di Desa Curug Kecamatan Gunung Sindur Kabupaten Bogor
}

\author{
Nining Latianingsih ${ }^{\mathrm{a}, 1, *}$, Dewi Winarni Suyanti ${ }^{\mathrm{b}, 2}$, Nunung Martina ${ }^{\mathrm{b}, 3}$, Iis Mariam ${ }^{\mathrm{b}, 4}$ \\ ${ }^{a, b}$ Politeknik Negeri Jakarta, Jl. Prof. Siwabessy, Kampus Baru UI, Depok 16424, Indonesia \\ ${ }^{1}$ nining.latianingsih@bisnis.pnj.ac.id * \\ * corresponding author
}

ARTICLE INFO

Article History

Received,27-11-2020

Revised,12-01-2021

Accepted,20-01-2021

Keywords

Covid 19;

Catfish Farmers;

Digital Marketing

\begin{abstract}
Community Service Program, especially the Appropriate Technology Application Program (PPTTG) in the village of Curug, Gunung Sindur District, Bogor Regency, which involves the community, especially catfish farmers, in an effort to increase community economic empowerment and marketing of catfish farming crops. Since the occurrence of Covid-19 has become a problem and has had an impact on the business activities of catfish farmers in marketing the catfish harvest because the amount of catfish consumption needs has decreased due to the decreasing purchasing power of the people around the village of Curug, the price of catfish feed has tended to rise so this condition has add to the burden of new problems for the community. PPTTG program help catfish farmers in village Curug as partners to be able to market their catfish harvest through direct sales and digital (online) marketing so that economic income increases and is able to buy catfish feed at a reasonable price, provide training and business assistance. catfish. The solutions offered in dealing with partner problems in developing catfish marketing through websites and internet marketing 4.0, making dumplings from catfish, help establish a special cooperative for catfish farmers so that catfish farmers have a formal organization that can assist in capitalizing catfish farmer members, providing tools for catfish production. The results of the PPTTG are the establishment of cooperatives for catfish farmers, diversifying catfish products such as dumplings, online marketing of catfish (marketing strategy 4.0), and owning the copyright and production brand rights so that catfish farmers can run catfish farming more increased. As for the sustainability of this program, it is hoped that catfish farmers in the village of Curug can continue to maintain the potential of catfish business and increase economic income
\end{abstract}

\section{PENDAHULUAN}

Situasi pandemic covid-19 saat ini telah berdampak pada semua bidang usaha termasuk usaha budidaya ikan lele yang dilakukan oleh petani yang selama ini telah dilakukan. Kondisi yang dirasakan oleh petani ikan lele saat ini adalah adanya penurunan hasil penjualan usaha pasca panen ikan lele kepada masyarakat sebagai konsumen tetap ikan lele mencapai 50\% dari situasi normal sebelum covid-19 disebabkan harga jual ikan lele menjadi murah, penetapan PSBB juga telah memberikan andil pada hasil penjualan pecel ikan lele di warung makan karena tidak dapat menyantap makanan di tempat, dan harga pakan ikan lele yang cenderung naik. UP2M-PNJ yang melakukan kegiatan Pelaksanaan Penerapan Teknologi Tepat Guna (PPTTG) kepada masyarakat bekerjasama dengan pelaku usaha petani ikan lele sebagai mitra yang sudah ada di desa Curug, kecamatan Gunung Sindur Kabupaten Bogor.

Profil mitra petani ikan lele di Gunung Sindur. Dari data geografis dan kependudukan kabupaten Bogor maka mata pencaharian warga desa Curug merupakan buruh yang bekerja pada bidang peternakan, pertanian dan buruh di industri sebesar $44,15 \%$ yang mengalami peningkatan dari data sebelumnya yaitu 26,45\% . Kondisi peningkatan jumlah buruh di desa Curug disebabkan karena pengembangan pembangunan wilayah desa Curug yang terus meningkat seiring kondisi 
infrastruktur jalan yang baik yang menghubungkan perbatasn antara wilayah kabupaten Bogor dengan kota Tanggerang Selatan dan Banten.

Profil mitra dalam kegiatan PPTTG ini adalah Ketua Dusun Curug sekaligus anggota Curug Mitra mandiri dan ketua Kelompok Curug Mutiara yang telah memiliki anggota kelompok petani ikan lele. Pemetaan awal yang telah dilakukan tim PPTTG mengenai potensi daerah Curug adalah usaha petani ikan lele yang ada di desa Curug ternyata telah beroperasi dengan memberdayakan masyarakat khususnya yang tidak memiliki pekerjaan tetap sebagai petani dan buruh di sekitar tempat usaha. Melihat potensi tersebut maka kegiatan ini diproyeksikan pada pengembangan diversifikasi produk pengolahan ikan lele, melakukan pemasaran melalui marketing digital 4.0, pelatihan dan pendampingan tentang pemasaran online dan offline, pelatihan, pendirian koperasi serta memberikan alat penunjang produksi produk olahan ikan lele.

Permasalahan mitra petani saat ini selain potensi pengembangan usaha budidaya ikan lele dan harga jual ikan lele yang turun maka ada masalah lain dilihat dari perspektif makro ekonomi desa Curug yaitu lingkungan perumahan belum tertata dengan baik sesuai rancangan pengembanga wilayah hunian dan usaha, belum memiliki website khusus untuk pemasaran secara online yang saat pandemic covid-19 ini menjadi prioritas dalam pengembangan usaha UMKM, belum terbentuknya koperasi yang menjadi wadah usaha dan pengembangan usaha petani ikan lele, belum memiliki merek hasil produksi ikan lele sebagai ciri khas produk local desa Curug, masih terbatasnya jumlah mesin dan alat produksi yang dapat membantu petani ikan lele dalam produksi olahan daging ikan lele, harga bahan baku pakan yang cenderung naik. Manfaat dari kegiatan PPTTG ini adalah memberdayakan petani ikan lele desa Curug dalam mendapatkan penghasilan, mengenal teknologi pemasaran berbasis digital untuk hasil pasca panen ikan lele, memiliki koperasi sebagai wadah usaha formal petani ikan lele, serta pengetahuan dan keterampilan dalam pemanfaatan ikan lele yang variatif.

Adapun solusi yang ditawarkan dalam kegiatan PPTTG ini adalah: (a) penguatan kelompok petani ikan lele, (b) pengembangan usaha ikan lele pasca panen, (c) diversifikasi produk dari olahan ikan lele menjadi daging fillet, siomay, nugget, bakso, abon, atau kerupuk, (d) pemasaran melalui website yang mengoptimalkan teknololgi 4.0, (c) pendirian koperasi khusus untuk petani ikan lele, dan (f) pemberian peralatan kemasan dan meat grinder untuk memudahkan pengolan diversifikasi produk berbahan dasar daging ikan lele.

\section{PELAKSANAAN DAN METODE}

adalah dengan melibatkan para pihak dalam kegiatan PPTTG kepada masyarakat, yaitu: (a) Kelompok Petani Ikan Lele serta (b) Anggota masyarakat yang dibagi menjadi beberapa 4 perkelompok yang terdiri dari pelaku usaha ikan lele serta masyarakat usia produktif seperti RT/RW, PKK, Karang Taruna, dan masyarakat yang tidak memiliki pekerjaan tetap. Mempertimbangkan kondisi dan situasi pandemic covid-19 maka pelaksanaan kegiatan baik dari tim PPTTG-UP2MPNJ dan mitra tetap mengikuti aturan dari pemerintah melalui penerapan protokol kesehatan dengan menerapkan physical distancing/social distancing, memakai masker, cuci tangan serta membawa hand sanitizer.

PPTTG dimulai dengan melakukan PPTTG selaku mitra. Tahapan yang dilakukan adalah: (a) melakukan identifikasi kebutuhan masyarakat melalui survey pendahuluan, untuk mempelajari situasi kerja petani ikan lele pasca panen yang melibatkan aparatur desa serta mitra yang membantu pemetaan jumlah peserta pelatihan dan pendampingan usaha yang berminat dalam pengembangan usaha produksi ikan lele, (b) melakukan seleksi dari jumlah peserta yang terkumpul dari aparatur desa dan mitra petani ikan lele lele pasca panen melalui pemberdayaan masyarakat. Kegiatan PPTTG selanjutnya adalah pelatihan yang dilakukan dengan system offline merujuk pada protocol kesehatan dan peserta lainnya dapat mengakses secara online. Setiap kehadiran dalam pelatihan harus mengisi google form untuk dapat dijadikan bukti sebagai absen kehadiran peserta dalam prose pelatihan.

Kegiatan pelatihan meliputi (a) pelatihan membuat olahan dari daging ikan lele yang dapat bertahan lama dengan cara disimpan di lemari pendingin untuk selanjutnya dijual secara online maupun offline, (b) pelatihan pemasaran produk melalui online dengan menggunakan beberapa media social, misalnya : dilaksanakan dengan satu system penjualan 4.0 seperti dibuat kanal untuk 
penjualan seperti dilakukan oleh marketplace yang sudah ada dan besar di Indonesia, (c) pembuatan koperasi, dengan minimal anggota 20 orang karena koperasi sebagai wadah untuk kelompok petani ikan lele yang dapat dijadikan wadah organisasi dan kerjasama antar anggota, (d) adanya pendampingan untuk pendaftaran merek hasil produksi ikan lele Kegiatan PPTTG di desa Curug diakhiri dengan dilakukannya monitoring dan evaluasi, Untuk hasil produksi akan di daftarkan hak mereknya sehingga akan dilihat keberhasilan dari program ini, diharapkan banyak kemajuan yang diperoleh sehingga akan menjawab permasalah yang ada di masyarakat. Peserta yang sudah mengikuti pelatihan dapat mempraktekkan bagaimana membuat, mengorganisasikan, menentukan skala prioritas, dapat menerapkan bagaimana menangai masalah dalam dunia usaha serta akhirnya diharapkan menghasilkan masyarakat yang produktif dan wirausaha berbasis potensi unggulan daerah seningga akan membantu lapangan kerja bagi masyarakat sekitarnya serta terbangunnya sentra-sentra usaha di wilayah desa Curug.

\section{HASIL DAN PEMBAHASAN}

Kegiatan PPTTG dilaksanakan dengan melibatkan mitra petani ikan lele, aparatur desa dan unsur masyarakat lainnya. Peserta pelatihan yang hadir dibatasi hanya 20 orang dengan mempertimbangkan aturan protocol kesehatan dan peserta lainnya mengikuti melalui online. Materi yang diberikan dalam pelatihan PPTTG ini adalah pembentukan koperasi karena komunitas petani ikan lele belum memiliki koperasi, pemasaran digital mengenai ikan lele dan produk olah daging ikan lele (siomay), praktek membuat siomay dari daging ikan lele, serta pembukuan sederhana Akuntansi. Merujuk pendapat dari Suyanto (2002: 56) mengenai ikan lele bahwa sebenarnya ikan lele dapat hidup dengan baik di dataran yang rendah sampai daerah yang tidak terlalu tinggi. Sedangkan (Sunarma, 2004: 23) mengatakan bahwa dalam budidaya ikan lele akan berkembang dengan pesat karena pada dasarnya ikan lele dapat dibudidayakan pada yang dan menjadi.

Pemasaran ikan dan olahan daging ikan lele oleh mitra petani ikan lele desa Curug masih perlu pendampingan dan hal ini sejalan dengan pengertian yang suatu dalam, serta yang ditujukan untuk dari,2013. PPTTG ini juga membantu mitra petani ikan lele dalam pengembangan pemasaran produknya dengan berbasis digital, hal ini sejalan dengan pendapat lainnya (Wardhana, 2015) mengenai pemasaran digital yang relevan dengan kegiatan PPTTG ini adalah bahwa pada dasarnya digital telah mengubah cara manusia berbicara, berkomunikasi, bertindak, dan mengambil keputusan, digital marketing diartikan sebagai kegiatan marketing yang termasuk branding menggunakan media berbasis online.

Hasil penelitian (Yacub dan Mustajab, 2020) bahwa digital marketing dan brand awareness pada pengguna media social berdasarkan tanggan dari responden memiliki nilai tertinggi dari responden terhadap dimensi variable digital marketing adalah instagram sebsar 85,65\% dan nilai terendah adalah twitter sebesar 54,5\%, tanggapan untuk responden mengenai awareness sebesar $79,4 \%$. Hasil ini menggambarkan bahwa saat ini pemasaran melalui online dan media social menjadi pilihan masyarakat dalam melakukan pemasaran baik untuk produk maupun jasa dan dapat dijadikan pembanding untuk dapat diterapkan dalam kegiatan usaha ikan lele masyarakat di desa Curug kabupaten Bogor melalui kegiatan program UP2M-PNJ dan PPTTG. Berikut gambar mengenai peralatan mesin penggiling daging untuk pengolahan daging ikan lele.

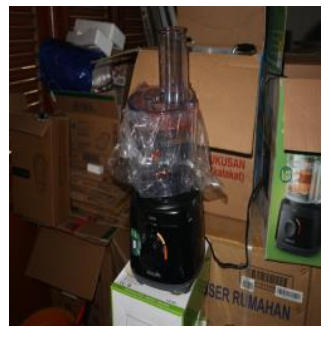

Gambar 3.3 Peralatan Meat Grinder

Alat penggiling daging ini digunakan untuk menggiling daging ikan lele yang akan dibuat untuk siomay. Adapun spesifikasi meat grinder ini adalah berat $17 \mathrm{~kg}$, ukuran 39x24 $8 \mathrm{~cm}$, Power : 0,37 kw, Voltage : 110$220 \mathrm{v}$, Frequency : 50/60 hz Efficiency : $80 \mathrm{~kg} / \mathrm{h}$. Berikut adalah mesin hand sealer yang akan digunakan oleh komunitas petani ikan lele desa Curug, kecamatan Gunung Sindur, Kabupaten Bogor. 


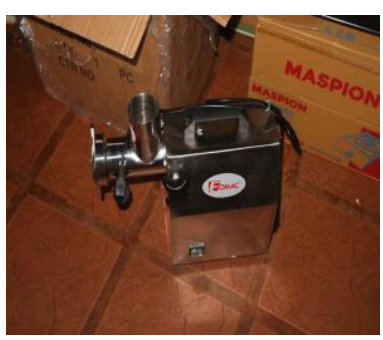

Gambar 3.2 Hand Sealer

Adapun spesifikasi hand sealer ini memiliki berat $2.3 \mathrm{~kg}$ dengan ukuran $42 \times 8.5 \times 8.5 \mathrm{~cm}$, serta Power : $400 \mathrm{w}$ dan Voltage : 220 v. Selanjutnya chest freezer sebanyak dua buah juga diberikan kepada komunitas petani ikan lele agar ikan lele dapat dan olahan daging ikan lele dapat disimpan lebih tahan lama.

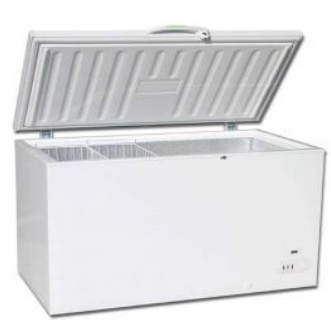

Gambar 3.3 Chest Freezer

Chest freezer ini memiliki spesifikasi alat dengan

berat $24 \mathrm{~kg}$,

ukuran: $3 \times 56,2 \times 84,5 \mathrm{~cm}$

Suhu: $-15 \sim-260 \mathrm{C}$,

listrik $80 \mathrm{w}$,

kapasitas beku $7 \mathrm{~kg}$ dan

kapasistas simpan $60 \mathrm{~kg}$.

Prosedur kerja yang dilakukan untuk mendukung realisasi PPTTG adalah dengan petani ikan lele khususnya pasca panen di desa Curug, Kecamatan Gunung Sindur Kabupatan Bogor, memberikan sosialisasi kepada petani ikan lele untuk selalu memiliki sikap dan budaya kerja yang kuat dalam meningkatkan usahanya, serta adanya motivasi yang kuat dari peserta pelatihan dalam menjalankan bisnis ikan lele melalui online maupun offline.

Adapun partisipasi mitra dalam kegiatan PPTTG kepada masyarakat adalah dengan mempersiapkan ketersediaan tempat untuk kegiatan pelatihan budidaya ikan lele dan pemasaran melalui internet, membentuk koperasi sebagai wadah petani ikan lele dalam mendukung usahanya. Bentuk kegiatan evaluasi dari PPTTG setelah pelaksanaan selesai oleh tim reviewer eksternal apakah kegiatan sesuai dengan perencanaan awal atau tidak sehingga hasil dari evaluasi yang positif dan baik akan menjadi rujukan kegiatan bisnis ikan lele oleh pihak eksternal.

Pada kegiatan dilakukan penyerahan barang peralatan dari UP2M-PNJ kepada Mitra yang diterima oleh ketua kelompok petani dan disaksikan oleh aparat desa, instruktur/pemateri serta peserta pelatihan.
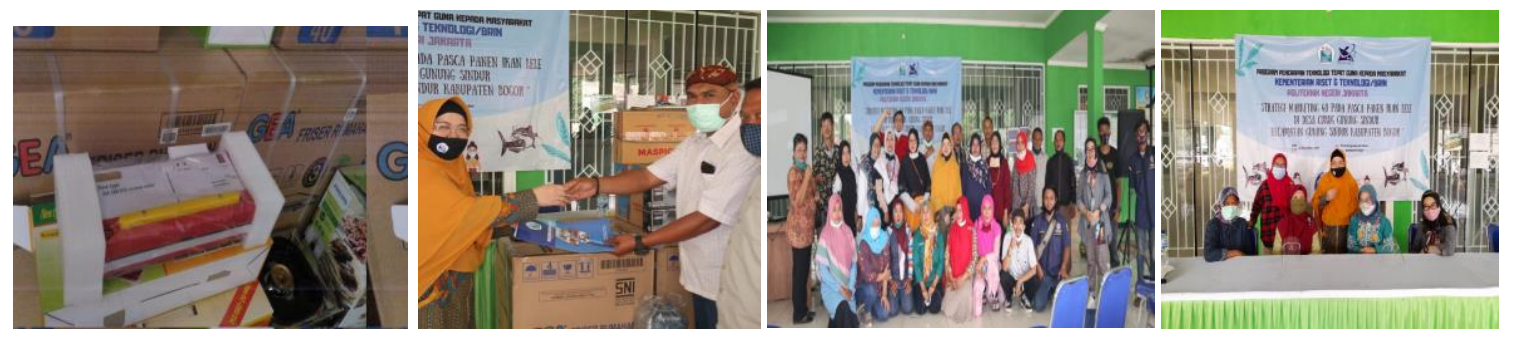

Gambar 5 Penyerahan Barang dan Peralatan

\section{PENUTUP}

\section{Simpulan}

Program penerapan teknologi tepat guna (PPTTG) yang dilakukan bersama dengan UP2M PNJ telah dilaksanakan pada komunitas petani ikan lele dengan baik sesuai rencana. Kegiatan PPTTG bertujuan untuk membantu mitra yaitu para petani ikan lele mendapatkan pendapatan ekonomi lebih baik pada masa pandemic covid-19. Kondisi pandemi telah menimbulkan masalah pada mitra petani ikan lele yaitu terjadinya penurunan pendapatan dari hasil panen ikan lele karena daya beli masyarakat berkurang, harga pakan ikan terus naik, serta pemasaran ikan lele yang masih konvensional.

Manfaat dari PPTTG ini adalah dengan memberikan pendampingan dan sosialisasi dalam bentuk pelatihan kepada mitra petani ikan lele desa Curug yang meliputi pelatihan pemasaran produk berbasis website/internet 4.0, membuat diversifikasi produk daging ikan lele yang diolah 
menjadi siomay dan abon ikan lele serta adanya pembentukan koperasi khusus petani ikan lele. Hasil kegiatan PPTTG ini adalah pengetahuan dan kemampuan petani ikan lele di desa Curug meningkat dalam pengelolaan budidaya ikan lele dan membantu pemberdayaan ekonomi masyarakat desa Curug, kabupaten Bogor. Hasil kegiatan PPTTG juga telah sejalan dengan implikasi teoritis dari (Assauri, 2013; Wardhana, 2015; Kotler dan Keller, 2016; Yacub dan Mustajab, 2020).

\section{Saran}

Saran yang dapat disampaikan untuk kegiatan pengabdian yang focus untuk pemberdayaan masyarakat dalam masa pandemic covid-19 adalah memberikan bantuan permodalan dan pendampingan usaha terutama dalam pemasaran produk yang mampu memberikan tambahan pendapatan bagi mitra petani. Bantuan teknologi tepat guna juga perlu dikembangkan sesuai dengan kebutuhan mitra setelah dilakukan evaluasi dan monitoring oleh reviewer internal dan eksternal UP2M-PNJ.

\section{DAFTAR PUSTAKA}

Assauri, Sofjan. (2013). Manajemen Pemasaran, Jakarta: Rajawali Press.

Purwana, Dedi. (2017). Pemanfaatan Digital Marketing Bagi usaha Mikro, Kecil, dan Menengah (UMKM) di Kelurahan Duren Sawit.

Priansa, Donni Junni. (2017). Perilaku Konsumen dalam Bisnis Kontemporer. Bandung: Alfabeta Khairuman, SP dan Khairul Amri. (2008). Buku pinter budidaya 15 ikan konsumsi. Jakarta: Agro

\section{Media Pustaka. \\ Edititon. Harlow: Pearson Education (2016).. (15e.USA.}

Sunarma, Ade. Produktivitas .Jurnal

Sugiyono. (2014). Metode Penelitian Bisnis. Bandung: Alfabeta

Suyanto, Rachamatun S. (2002). Budidaya Ikan Lele. Jakarta: Penebar Swadaya

Wardhana, Aditya. (2015). Strategi Digital Marketing dan Implikasinya pada Keunggulan Bersaing UKM di Indonesia.

Yacub, Rudi dan Wahyu Mustajab. (2020). Marketing Terhadap Brand Awarness Pada ECommerce. Manajerial-Jurnal Manajemen dan Sistem Informasi. http://ejournal.upi.edu/index.php/manajerial/ Vol. 12 No.2 Juni 2020, hal 198-208. 